\title{
PRIORIDADES PARA ÔNIBUS NOS PLANOS DE SINCRONISMO: O CASO DO RIO DE JANEIRO
}

\section{Paulo Cezar Martins Ribeiro}

Programa de Engenharia de Transportes

COPPE/UFRJ

\section{RESUMO}

O objetivo deste artigo é descrever os resultados alcançados na implantação dos planos semafóricos calculados pelo programa TRANSYT, sugeridos pelo manual do programa, quando prioridades para os ônibus nas vias principais do Rio de Janeiro são consideradas nos cálculos. Os critérios e facilidades apresentados no programa para estas prioridades tiveram como base o comportamento do tráfego na Inglaterra e Escócia, onde o programa foi desenvolvido e modelado. São realizadas comparações entre a composição típica do tráfego na Inglaterra e no Brasil, realizadas análises das experiências de priorizar ônibus (ou outro tipo veículo) em outras situações e países. É feita uma análise dos resultados obtidos na implantação de planos de sincronismo com prioridades para ônibus, conforme recomendado pelo manual do TRANSYT, através da comparação de várias situações relativos às simulações dos padrões e modelos de tráfego, bem como tipos de planos de sincronismo simulados. Finalmente são apresentadas as soluções temporárias encontradas para o uso dos planos de sincronismo e a indicação da necessidade de estudos específicos para a solução definitiva do problema.

\section{ABSTRACT}

This paper describes the results achieved when signal timing plans calculated by the TRANSYT program with bus priority are used with the values suggested by the program manual. The field trial was in the city of Rio de Janeiro. The criteria and facilities presented by the program manual for that kind of priority were based on the behaviour of the traffic in the UK where the program was developed and modelled. There are comparisons between the traffic composition in the UK and Brazil, analysis of the previous experiences in bus (or other kind of vehicles) priorities, in other type of traffic situation and countries. There is an analysis of the results achieved when the signal timing plans calculated as the manual of TRANSYT suggests are implemented in the Rio de Janeiro city centre. This is made by 
comparisons between several scenarios regarding different patterns of traffic and traffic signal plans. Finally, it is presented temporary solutions to be used in the calculation of signal timing plans and the need for research required for more permanent achievements.

\section{INTRODUÇÃO}

O objetivo deste artigo é descrever os resultados alcançados na implantação dos planos semafóricos calculados pelo programa TRANSYT 9 (Crabtree, 1988), de acordo com os procedimentos sugeridos pelo manual do programa, quando são consideradas nos cálculos as prioridades para os ônibus nas vias principais do Rio de Janeiro. O programa TRANSYT, desde sua versão 5 (Peirce e Wood, 1977), dispõe da facilidade de poder representar ligações exclusivas para ônibus. Nestas ligações, é possível considerar os tempos despendidos pelos coletivos nos pontos de parada e representar as velocidades próprias dos ônibus, diferentes dos demais veículos. Também é possível atribuir pesos para os atrasos e paradas, diferenciados para os "links" de ônibus para os demais links.

Os critérios e as facilidades apresentados no TRANSYT tiveram como base o comportamento do tráfego na Inglaterra e Escócia, onde este programa foi desenvolvido e modelado. Conforme consta no manual do TRANSYT, a composição típica do tráfego urbano na Inglaterra é: 82 por cento de automóveis, 9 por cento de veículos leves de carga, 8 por cento de ônibus e caminhões médios/pesados e 1 por cento de motocicletas. O comportamento dos ônibus, conforme é simulado pelo programa, vem sendo discutido e comentado em inúmeros artigos e congressos. Neste artigo, são apresentadas algumas constatações oriundas das observações de campo, decorrentes da implementação dos planos semafóricos desenvolvidos para a área central do Rio de Janeiro, onde o comportamento do tráfego e as porcentagens dos ônibus são distintos dos verificados nos países onde o TRANSYT foi desenvolvido e modelado.

\section{MÉTODOS EXISTENTES}

O comportamento dos ônibus no sistema viário é diferente do comportamento dos automóveis. Os ônibus têm características físico-operacionais distintas dos automóveis no que diz respeito à vários fatores. Tal fato induziu o desenvolvimento de técnicas específicas para o tratamento dos fluxos de ônibus em interseções semaforizadas, seja em relação às interseções 
individuais, seja em relação às redes de semáforos coordenados. Uma das ferramentas mais importantes para a adoção de prioridades para o transporte coletivo no tráfego misto é o programa TRANSYT, que diferencia e proporciona a introdução de prioridades para os links de ônibus. A modelagem dos ônibus foi baseada em pesquisas e técnicas desenvolvidas na Inglaterra e Escócia e simulam de maneira adequada o comportamento destes veículos na corrente de tráfego daqueles países. Segundo Peirce e Wood, os aspectos operacionais que diferenciam os ônibus do tráfego de automóveis são, principalmente:

- velocidades

- pontos de parada

- tempos de viagem

- rotas fixas

Levando em consideração estas características operacionais dos ônibus, foi possível elaborar uma modelagem adicional para o tráfego, possibilitando a introdução de prioridades para os ônibus, disponível desde a versão 5 do programa, também chamado Bus TRANSYT.

Willumsen e Coeymans (1989) analisaram a eficiência dos planos de tempo fixo, calculados pelo programa TRANSYT, em Santiago. A modelagem dos ônibus foi um dos pontos que mereceu atenção especial, devido às características particulares do sistema de transporte coletivo por ônibus naquela cidade, a começar pelos elevados volumes de ônibus em suas vias. O setor de transporte público por ônibus estava récem-desregulamentado, propiciando a criação de uma grande quantidade de pequenas empresas, com veículos operados, em sua maioria, pelos proprietários, através da chamada "operação individual", onde o motorista acumula as funções de motorista e cobrador. Embora existissem pontos de ônibus regulamentados, estes não eram usados pelos usuários, nem obedecidos pelos motoristas. $O$ elevado número de ônibus em operação criava áreas (ou "manchas") para o embarque/desembarque dos passageiros, no lugar dos pontos de parada. Além disso, os ônibus permaneciam nessas áreas, aguârdando potenciais usuários, ou se "arrastavam" junto ao meio-fio à procura de passageiros. Tais características fizeram com que a eficiência dos planos de sincronismo ficasse comprometida. A solução encontrada pelos autores foi a modificação do fator de dispersão de pelotões dos links de ônibus. Este fator considera o tempo médio de paradas e o tempo médio de percurso para calcular a 
dispersão dos ônibus ao longo de um link. A função deste fator é apresentada abaixo.

$$
F=\frac{1}{(1+a \cdot S T+b \cdot R T)}
$$

onde:

F é o fator de alisamento, ou dispersão, de pelotões para ônibus;

$\boldsymbol{a}$ e $\boldsymbol{b}$ são constantes, respectivamente iguais a 0,7 e 0,35;

$S T$ é o tempo médio de parada num ponto; e

$R T$ é o tempo médio de viagem num link.

As pesquisas mostraram que havia uma melhora no desempenho do tráfego quando era alterado o coeficiente da variável relativa ao tempo médio de percurso dos ônibus (b). Não foram observadas melhorias significativas quando se alterava o fator relativo ao tempo médio de parada (a). No entanto, o programa TRANSYT não permite que o usuário mude as constantes (a e b) da fórmula do fator de dispersão de pelotões de ônibus. Tais alterações só são possíveis através de modificações no código do programa (realizadas por Willumsen e Coeymans), não acessíveis ao usuário.

Joyce e Yagar (1990) apresentaram uma forma não-convencional de representar os efeitos dos tempo gastos por Veículos Leves Sobre Trilhos (VLT) no cálculo de planos de tempo fixo, simulando a operação dos VLTs nas faixas centrais de uma via no Canadá (Queen Street, em Toronto). Quando o VLT faz uma parada para o embarque/desembarque de passageiros, ele bloqueia a passagem de outros veículos. Porque os VLTs não estão presentes em todos os ciclos, os autores dividiram os fluxos de automóveis em duas correntes paralelas, compartilhando a linha de retenção: uma representando os veículos que são afetados pela operação do VLT no ponto de parada e outra para representar os que não são afetados. Para simular o comportamento do. tráfego nas redondezas da interseção eles usaram links e nós fictícios. Para cada ponto de parada do VLT é necessário um nó fictício e quatro links fictícios. Durante uma operação normal, as correntes de tráfego formadas pelos automóveis é forçada a parar atrás de um VLT e esperar próximo à interseção durante o tempo que o VLT gasta para embarcar/desembarcar passageiros. Isto é simulado alocandose os links fictícios designados para os VLTs e para os automóveis em 
estágios diferentes, dando uma alta prioridade aos VLTs em relação aos automóveis, num nó fictício com dois estágios. A distribuição discreta dos tempos de embarque/desembarque em cada parada é representada por uma distribuição de dois pontos com mesma média, variância e esconsidade da distribuição original. Esta distribuição de dois pontos é usada para obter os tempos de embarque/desembarque, que são usados como tempos de amarelo nos links fictícios. Deve ser ressaltado que os autores consideram que a presença do VLTs não são registradas em todos os ciclos, ou seja, os volumes desse veículos são baixos.

Objetivando modelar a interferência das operações dos ônibus nos pontos de embarque/desembarque de passageiros, Silva, Portugal e Santos (1993) desenvolveram outro método, similar ao desenvolvido por Joyce e Yagar, pois faz uso de nós e links fictícios. Neste caso, a interferência das operações dos ônibus nos pontos de parada no meio de um link é simulado por uma interseção com prioridades (não semaforizada) Este método, porém, ainda não foi testado em campo.

Todos os estudos de simulação do comportamento do fluxo de ônibus nos planos de sincronismo semafórico, de tempo fixo, calculados pelo programa TRANSYT são baseados na observação feita no manual do programa (Vincent et al., 1980), de que os prejuízos ao fluxo de automóveis são desprezíveis, em comparação aos benefícios dados aos ônibus. A Figura 1, ilustra os efeitos das prioridades para ônibus nos planos de sincronismo, quando são levados em conta as características dos pelotões de veículos e de um único ônibus. A análise desta figura mostra que a influência no sistema progressivo do tempo de parada do veículo no ponto, não é significativa, em função do pequeno peso que ele exerce, neste caso particular. O retardamento imposto aos automóveis é reduzido pois a influência de um só ônibus é pequena. Além disso, o instante que está sendo considerado, para a passagem do ônibus pelo SEMÁFORO 1 é tal que não são causadas grandes perturbações na progressão, ou seja, é possível passar pelos SEMÁFOROS 1 e 2, priorizar o movimento de um ônibus que pára num ponto intermediário e não causar atrasos consideráveis ao fluxo de automóveis.

Tendo em vista a impossibilidade de acessar os códigos do programa TRANSYT 9 e o fato do método deSilva etal (1993) ainda não ter sido testadoem campo, optouse, nesteestudo, pelo uso das prioridades para ônibus conforme os procedimentos sugeridos pelo manual do referido programa. 


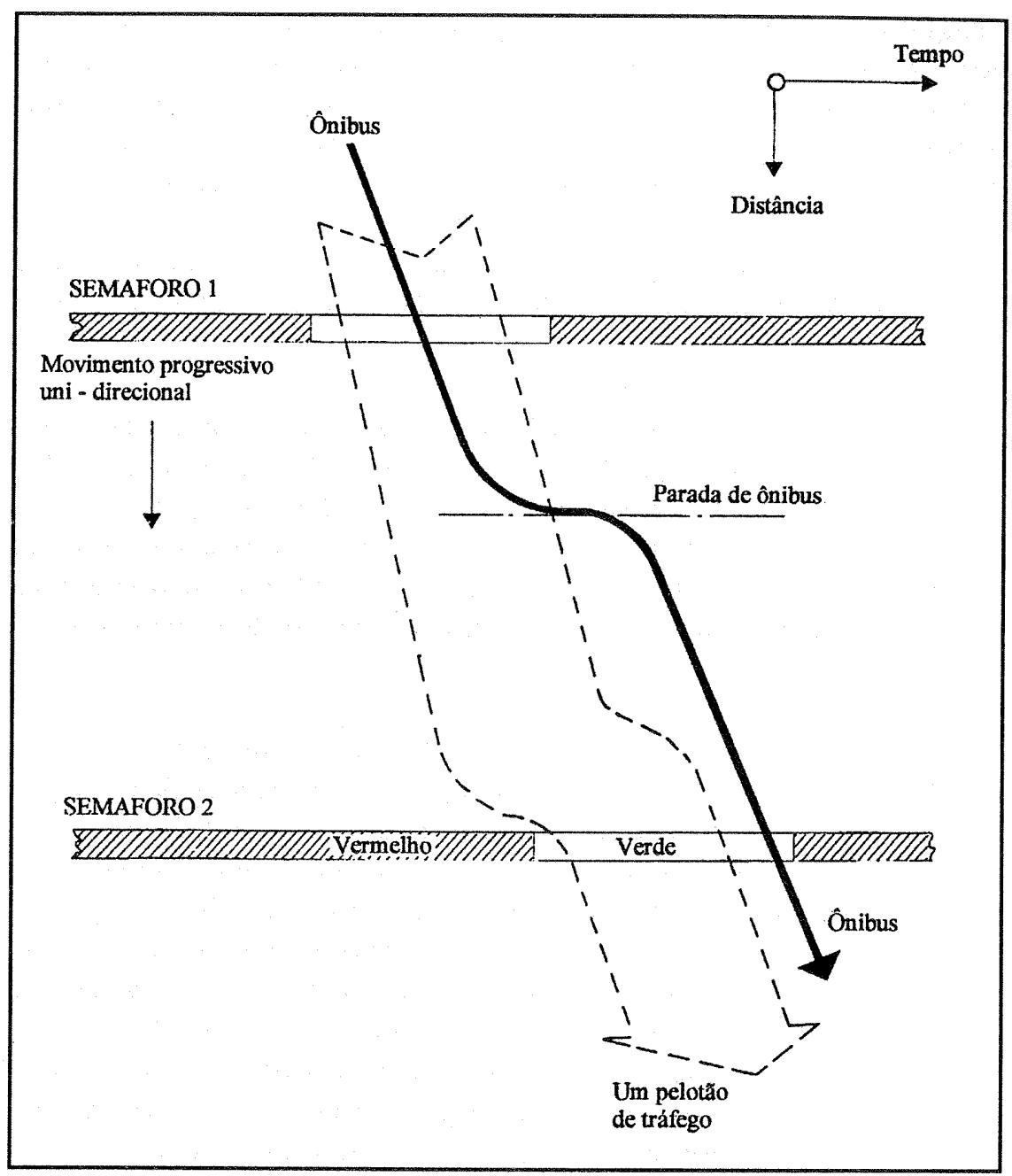

Figura 1 - Diagrama Espaço-Tempo Mostrando os Diferentes Movimentos Típicos de um Pelotão de Veículos e Um Ônibus

Fonte: VINCENT, R.A., MITCHELL, A.I. and ROBERTSON, D.I. (1980) User Guide to TRANSYT version 8. Transport and Road Research Laboratory LR 888, Crowthorne 


\section{O SISTEMA DE ÔNIBUS NO RIO DE JANEIRO}

Na cidade do Rio de Janeiro, o transporte coletivo por ônibus ocupa um lugar de destaque. Na Região Metropolitana, por exemplo, o sistema de ônibus é responsável por 8.043 .786 viagens diárias, correspondentes à $61,02 \%$ do total de viagens (IPLAN-RIO, 1995). O sistema de ônibus opera de acordo com as seguintes características:

- é um setor regulamentado

- os veículos pertencem, em sua maioria, à empresas de grande porte

- as empresas operam linhas regulares

- os pontos de parada são definidos, embora a grande quantidade de veículos em operação induza ao prolongamento dos pontos, formando as áreas (ou "manchas") de parada, já identificadas por Willumsen e Coeymans, em Santiago

- os veículos são operados, em sua quase totalidade, por duas pessoas (motorista e cobrador).

Uma das características mais marcantes do tráfego de veículos no Rio de Janeiro é aquela relativa aos volumes e percentuais de ônibus nas vias das grandes cidades. Na Tabela 1, abaixo, são apresentados, a título de ilustração, os percentuais médios dos ônibus, em relação ao tráfego total, verificados em duas importantes vias do Centro da cidade do Rio de Janeiro: a Avenida Rio Branco e a Rua $1^{\circ}$ de Março. Cabe salientar que estes percentuais também são encontrados em outras vias-corredores da cidade, usadas pelo sistema de ônibus em seus itinerários regulares.

Tabela 1 - Fluxos e porcentagens de ônibus no RJ

\begin{tabular}{|l|c|c|c|c|}
\hline \multirow{2}{*}{ PERíoDo } & \multicolumn{2}{|c|}{ Av. Rio Branco (1) } & \multicolumn{2}{c|}{ Rua 10 de Março (2) } \\
\cline { 2 - 5 } & fluxo de ônibus & \% do fluxo total & fluxo de ônibus & \% do fluxo total \\
\hline Pico da Manhã & 568 & 27 & 456 & 30 \\
\hline Entre-pico & 460 & 19 & 412 & 21 \\
\hline Almoço & 440 & 19 & 416 & 22 \\
\hline Entre-pico & 460 & 22 & 428 & 22 \\
\hline Pico da Tarde & 340 & 17 & 540 & 31 \\
\hline
\end{tabular}

1 - trecho entre a R. do Ouvidor e R. Sete de Setembro

2 - trecho entre a R. Sete de Setembro e R. do Ouvidor 
Os valores constantes da Tabela 1 contrastam com os valores considerados típicos na Inglaterra, para o percentual de ônibus e caminhões médios/ pesados que, segundo o manual do TRANSYT 8 (Vincent et al., 1980), é da ordem de $8 \%$. Em cidades menores, este percentual está compreendido entre 2 e $5 \%$. Mais do que o valor do percentual dos ônibus em relação ao tráfego total, impressiona o valor absoluto do fluxo de ônibus. Enquanto são considerados como normais os valores apresentados no exemplo (UGUIDE) do manual do TRANSYT 8, da ordem de 50 ônibus por hora os valores absolutos da tabela estão num intervalo de 340 à 568 ônibus por hora. Na presença de valores para os fluxos de ônibus, como os apresentados na Tabela 1, significativamente diferentes daqueles constantes no manual do TRANSYT, o estabelecimento de prioridades para ônibus, poderá provocar prejuízos à circulação dos automóveis, principalmente em vias com altos índices de saturação.

\section{ESTUDO DE CASO}

Para analisar com mais detalhes a eficiência dos planos de sincronismo calculados pelo programa TRANSYT 9, foi escolhida a Avenida Rio Branco. Esta via é uma das principais artérias do centro da cidade e faz parte do Módulo I do Sistema Centralizado de Controle de Tráfego da Cidade do Rio de Jane ro. A Avenida Rio Branco tem 6 faixas de rolamento, sendo duas faixas indicadas como tendo prioridade para a circulação dos ônibus. Possui aproximadamente $1830 \mathrm{~m}$ de extensão, 22 cruzamentos, sendo 17 interseções semaforizadas, todas com altos índices de saturação e 5 exclusivas para pedestres. $\mathrm{O}$ cruzamento desta via com a Av. Presidente Vargas é considerada a interseção mais importante de todo o sistema.

A análise do desempenho dos planos de sincronismo foi realizada através da observação das variáveis abaixo relacionadas, medidas diretamente em campo:

- tempos de viagem ao longo da avenida (com uso de veículo-teste)

- filas máximas de veículos nas linhas de retenção das interseções

Foram avaliadas 4 situações (cenários) distintas, cada uma com planos semafóricos com características próprias:

- o plano original - cenário 0 
- um "plano de partida" - cenário 1

- um plano sem prioridades para os ônibus - cenário 2

- um plano com prioridades para ônibus - cenário 3

A seguir é feita uma descrição mais detalhada de cada um destes cenários:

\section{Cenário 0}

O cenário 0 representa a situação da Avenida Rio Branco antes da implantação do Sistema de Controle de Tráfego Centralizado da cidade do Rio de Janeiro. Neste caso, os controladores são operados pelo antigo sistema de controle de tráfego, instalado há aproximadamente 15 anos. Os planos de sincronismo estão inteiramente desatualizados e o grau de degradação do hardware do sistema é muito alto, funcionando precariamente. Além disso, sérios problemas de comunicação entre a Central de Controle e os controladores locais implica na operação com um único plano, o plano local, durante todo o dia, em várias interseções.

\section{Cenário 1}

Neste cenário, já estão sendo usados os novos controladores de tráfego na Av. Rio Branco. Os planos de sincronismo, calculados pelo TRANSYT 9, foram implantados e são usados 5 planos diferentes ao longo do dia, para o gerenciamento das diferentes condições do tráfego. Embora os planos de sincronismo sejam compostos por tempos de verde e defasagens distintos para cada plano, projetado para uma condição de tráfego específica, neste cenário só foram usados os tempos de verde. As defasagens, foram todas assumidas com o valor 0 para possibilitar uma verificação "in loco" da implantação adequada dos planos de sincronismo. Este procedimento foi necessário porque, nessa época, o centro de controle do sistema ainda não estava completamente operacional, apresentando problemas de comunicação com os controladores locais e a verificação da implantação correta do plano semafórico tinha que ser realizada na via.

\section{Cenáário 2}

Neste cenário, os planos de sincronismo foram calculados sem as prioridades para ônibus. Foi usado apenas um "link" representando as ligações entre os pares de nós e os fluxos usados representam o tráfego 
misto, em unidades de carros de passageiros (ucp). Os fatores de conversão são os recomendados por Webster e Cobbe (1966) ${ }^{1}$. Esta é uma das configurações possíveis para o cálculo de planos através do programa TRANSYT. Neste cenário, os planos de sincronismo foram implantados integralmente, isto é, foram usados os tempos de verdee as defasagens. Da mesma forma que no cenário 1, foram usados 5 planos ao longo do dia.

\section{Cenário 3}

Este cenário representa a situação do sistema de controle de tráfego quando os planos de sincronismo implantados foram calculados pelo TRANSYT 9, com todas as facilidades disponíveis no programa, no que se refere às prioridades para ônibus. Para a introdução destas prioridades foram adotados pesos de equivalência nas ligações dos ônibus, tanto para a parada, quanto para o tempo gasto nos sinais de tráfego à espera da indicação verde, que representassem uma importância relativa para os ônibus 20 vezes maior do que para os automóveis. Este valor (20) representa a diferença entre as taxas de ocupação dos ônibus e dos automóveis. Assim, o uso destes fatores de peso faz com que o TRANSYT 9 calcule planos de sincronismo para os usuários motorizados do sistema, em lugar de planos para os veículos. O outro fator necessário à implantação das prioridades para ônibus, o tempo gasto nas paradas para embarque/desembarque de passageiros, foram levantados em campo, na própria Av. Rio Branco.

Dentre os 4 cenários descritos, apenas os 3 primeiros serão considerados, pois os resultados obtidos com a implantação dos planos adotados no último cenário (3) não foram satisfatórios, ou seja: o uso das prioridades para ônibus fez com que os fluxos de automóveis ficassem prejudicados de tal forma que causaram transtornos à circulação dos próprios ônibus. Os transtornos, medidos por graus de saturação elevados, filas bloqueando as interseções à montante, atrasos excessivos, etc., foram de tal monta que a operação com estes planos foi rapidamente suspensa, antes mesmo que fossem realizados levantamentos visando à sua avaliação.

\footnotetext{
${ }^{1}$ Fatores de Equivalência usados:

ônibus $=2.25$ ucp

caminhão $=1.75$ ucp
} 
A avaliação foi feita pela medição dos tempos de viagem e tamanho das filas nas linhas de retenção, medidos em campo. Estes levantamentos foram realizados nos 5 horários que usavam planos de sincronismo distintos, normalmente operados durante um dia útil. Os horários foram:

- pico da manhã (PM):

$07: 00$ às $10: 00$

- entre pico da manhã (EM):

$10: 00$ às $12: 00$

- $\operatorname{almoço~(AM):~}$

$12: 00$ às $14: 00$

- entre pico da tarde (ET):

$14: 00$ às $16: 00$

- pico da tarde (PT):

$16: 00$ às $19: 00$

Estes levantamentos foram realizados, para os diversos cenários. Assim foi possível estabelecer comparações entre o desempenho dos diversos planos, correspondentes aos diferentes cenários, ao longo de toda a Avenida Rio Branco. Foram realizados levantamentos em número suficiente para ultrapassar os 10 a 12 pontos de observação, que foram os valores considerados, por Willumsen e Coyemans (1989), como necessários para obtenção de significância estatística. Os valores são apresentados nas tabelas abaixo. Na tabela 2, são apresentados os valores dos diversos tempos de percurso.

\begin{tabular}{|c|c|c|c|}
\hline \multirow{2}{*}{ HORÁRIO } & \multicolumn{3}{|c|}{ CENÁRIO } \\
\hline & 0 & 1 & 2 \\
\hline PM & $8: 00$ & $5: 52$ & $4: 37$ \\
\hline EM & 10:00 & $8: 23$ & $4: 16$ \\
\hline AM & ND & $6: 19$ & $4: 37$ \\
\hline ET & ND & $9: 56$ & $8: 36$ \\
\hline PT & ND & $10: 36$ & $7: 58$ \\
\hline
\end{tabular}

Tabela 2 - Tempos de viagem (min)

ND - Não Disponível. Estes dados referem-se aos antigos planos de sincronismo e não foram levantados.

Foram realizados levantamentos das filas nas interseções, somente para os cenários 1 e 2 (não haviam registros de filas para o cenário 0). Os valores observados são apresentados na Tabela 3. Estes levantamentos foram realizados nas interseções mais importantes da Av. Rio Branco: 
Tabela 3 - Filas máximas (ucp) da interseção

da Av. Rio Branco com as vias indicadas

\begin{tabular}{|l|c|c|c|c|c|c|c|c|c|c|}
\hline & \multicolumn{2}{|c|}{$\begin{array}{c}\text { Mar. Floriano } \\
\text { Cenário }\end{array}$} & \multicolumn{2}{c|}{$\begin{array}{c}\text { Pres. Vargas } \\
\text { Cenário }\end{array}$} & \multicolumn{2}{c|}{$\begin{array}{c}\text { Buenos Aires } \\
\text { Cenário }\end{array}$} & \multicolumn{2}{c|}{$\begin{array}{c}\text { Assembléia } \\
\text { Cenário }\end{array}$} & \multicolumn{2}{|c|}{$\begin{array}{c}\text { Evaristo Veiga } \\
\text { Cenário }\end{array}$} \\
\hline Horário & 1 & 2 & 1 & 2 & 1 & 2 & 1 & 2 & 1 & 2 \\
\hline PM & 6 & 3 & 18 & 18 & 9 & 10 & 13 & 5 & 9 & 6 \\
\hline EM & 4 & 3 & 15 & 17 & 11 & 10 & 11 & 5 & 9 & 7 \\
\hline AM & 4 & 2 & 16 & 17 & 12 & 11 & 14 & 5 & 9 & 7 \\
\hline ET & 5 & 2 & 15 & 16 & 13 & 13 & 16 & 7 & 9 & 8 \\
\hline PT & 17 & 3 & 22 & 15 & 20 & 10 & 19 & 7 & 10 & 9 \\
\hline
\end{tabular}

A observação das tabelas apresentadas, permite inferir resultados sobre o desempenho dos planos em cada cenário. Tais inferências são baseadas nas variáveis tempo de percurso e filas nas aproximações das interseções.

A análise do tempo de percurso, realizados para os cenários 0,1 e 2, permite verificar a existência de uma redução no tempo de percurso no cenário $2 \mathrm{em}$ relação aos outros dois cenários. Surpreendentemente os tempos de percurso do cenário 1 são menores do que os do cenário 0 . Tal não deveria ocorrer pois, mesmo desatualizados, os planos do cenário 0 são sincronizados e deveriam ter um desempenho melhor que os do cenário 1, que representam uma situação onde as defasagens são nulas.

Em relação às filas de veículos, a análise da tabela 3 permite verificar que o cenário 2 produziu melhores resultados (isto é, filas menores) do que o cenário 1. Isto era esperado, pois o cenário 1 foi implantado com splits e defasagens, enquanto no cenário 2 só foram implantados os verdes. A diferença entre o tamanho das filas dos cenários 1 e 2 é significativa, à exceção das filas verificadas na interseção das Av. Rio Branco e Pres. Vargas, que encontra-se saturada. A fila da Av. Buenos Aires também deve ser analisada com cautela pois esta é uma interseção de pedestres. Durante todos os períodos o tamảnho das filas é semelhante, à exceção do pico da tarde onde se verifica uma redução na fila do cenário 2 em relação ao cenário 1. No entanto, a fila do cenário 2 , neste período, é significativamente maior que o valor médio encontrado nos demais períodos. 


\section{CONCLUSÕES}

Os planos calculados com as prioridades para ônibus, de acordo com as recomendações do manual do TRANSYT, provocaram, na prática, transtornos para a fluidez normal do trânsito, principalmente dos automóveis, contrariando as observações constantes no próprio manual (de que a introdução de prioridades para os ônibus não afeta o tráfego de automóveis). Como os níveis dos fluxos de ônibus no Rio de Janeiro são extremamente elevados, a representação dos movimentos de acordo com a Figura 1 não é válida para o caso analisado.

Com base nos dados apresentados no item 4, foi adotado, como solução temporária, um plano sem prioridades para os ônibus. Este plano resolveu satisfatoriamente os congestionamentos verificados na Av. Rio Branco. Esta solução deve ser adotada temporariamente, enquanto não forem executados estudos específicos visando definir como atribuir prioridades para os ônibus nos planos de sincronismo semafórico calculados pelo programa TRANSYT, na cidade do Rio de Janeiro, em função dos altos volumes de ônibus e características próprias de seu tráfego.

Os estudos realizados por Willumsen e Coeymans (1989) são os únicos que foram testados efetivamente em campo e podem ser tomados como ponto de partida para uma adaptação efetiva do programa TRANSYT para uso no Rio de Janeiro. A sugestão daqueles autores, de que as mudanças no fator de dispersão de pelotões de ônibus são suficientes para produzir planos eficientes, deve ser considerada na busca de uma expressão que seja válida para o Rio de Janeiro. No entanto, modificações nos parâmetros do fator de dispersão de pelotão dos ônibus requer alterações nos códigos do programa, o que pode ser um elemento complicador.

Deve ser analisada cuidadosamente a importância, ou pesos, das paradas e atrasos nos links de ônibus. Os valores usados no Cenário 3 foram baseados na proporção 1/ 20 para o carregamento dos automóveis e ônibus, ou seja, 1 ônibus transporta, em passageiros, o equivalente a 20 automóveis. Tal valor pode estar gerando uma importância exagerada aos fluxos de ônibus em relação aos automóveis. Como as vias estão com graus de saturação bastante altos, o fluxo de automóveis fica penalizado gerando filas que acabam prejudicando os próprios ônibus. 


\section{AGRADECIMENTOS}

O autor agradece à Companhia de Engenharia de Tráfego do Rio de Janeiro (CET-RIO), o uso dos dados levantados durante o "Projeto de Implementação do Sistema de Controle de Tráfego da Cidade do Rio de Janeiro", executado pela Fundação Coppetec, para a CET-Rio, no desenvolvimento dos conceitos nos quais este artigo se baseia.

\section{REFERÊNCIAS}

IPLAN-RIO. (1995) Processo de Estruturação dos Transportes na Região Metropolitana do Rio de Janeiro. TOMO3A

JOYCE, P. and YAGAR, S. (1990)Representing stochastic transyt times in traffic signal optimisation. Transportation Research , 24A(2), 87-98

PEIRCE, J.R. and WOOD, K. (1977) BUS TRANSYT - a user's guide. Transport and Road Research Laboratory SR 266, Crowthorne.

SILVA, P.C.M., PORTUGAL, L.S. e SANTOS, M.P.S. (1993) Modelagem to Comportamento dos Fluxos de Ônibus no TRANSYT 8. Anais do $7^{\circ}$ Congresso da ANPET, São Paulo, 809-820

VINCENT, R.A., MITCHELL, A.I. and ROBERTSON, D.I. (1980) User Guide to TRANSYT version 8. Transport and Road Research Laboratory LR 888, Crowthorne

WEBSTER, F.V. and COBBE, B.M. (1966) Traffic signals. Road Research Technical Paper No. 56. HMSO, London.

WILLUMSEN, L.G. and COEYMANS, J.E. (1989) The value of fixed-time signal co-ordination in developing countries II. Improved bus modelling and results. Traffic Engineering and Control, 30(3), 126-13 